\title{
Pai e filha, Não por acaso: cotidiano, lugar e deslugar ${ }^{1}$
}

\section{Sandra Fischer}

Universidade Tuiuti do Paraná

1. Uma versão preliminar deste trabalho foi apresentada no XIII Encontro Internacional Socine (Sociedade Brasileira de Estudos de Cinema e Audiovisual), realizado na escola de Comunicações e Artes da Universidade de São Paulo (ECA/USP) em 2009. 
Resumo $O$ trabalho explora a dimensão poética das configurações imagéticas que delineiam, nos filmes Pai e filha (Japão, 1949, Yasujiro Ozu) e Não por acaso (Brasil, 2007, Philippe Barcinski), o lugar do deslugar no cotidiano. A partir dos lugares que se estabelecem no bojo dos nós que regulam as teias dos relacionamentos sociais que se articulam no dia-a-dia, examinaremos, considerando os dois universos fílmicos, os deslugares que se instalam nas brechas que perfazem essas mesmas teias.

\section{Palavras-chave}

cinema, cotidiano, deslugar, Pai e filha, Não por acaso

\section{Abstract}

The article explores the poetic dimension Late Spring (Japan, 1949, Yasujiro Ozu) and Não por acaso (Brazil, 2007, Philippe Barcinski) focusing on everyday life images presented in both films and emphasizing, considering the matter of the established places and positions settled in the course of ordinary social relationships, the installation of a dimension that we are calling deslugar.

\section{Key-words}

cinema, daily routine, deslugar, Late Spring, Não por acaso 


\section{Cinema, cotidiano, (des) lugar}

2. Fundado na problemática da dimensão estética do cinema, o projeto a que me refiro encontra-se alicerçado em preceitos teóricos advindos de estudos contemporâneos de cinema e de estudos estéticoculturais. Desenvolve-se na esteira de pesquisadores como, entre outros,

Michel de Certeau (com suas teses e discussões a respeito do que denomina a invenção do cotidiano pelo homem ordinário e anônimo),

Gilles Deleuze e Félix Guattari (rizoma, desterritorialização), Michel

Maffesoli (experiência individual e experiência coletiva), Marc Augé

(o conceito de não lugar e seus desdobramentos), Gaston Bachelard

(questões relativas à poética do espaço), Jean-Marie Floch (noções a respeito das relações semi-simbólicas

e suas correlações), Jacques Lacan (naquilo que se refere a tópicos como linguagem, Real, desejo), e Zygmunt Bauman (fluxos, vida líquida, sociedade líquido-moderna).
As reflexões e as proposições que apresento neste artigo fazem parte de uma série de estudos inserida no âmbito de um projeto de pesquisa no qual venho investigando no cenário do cinema brasileiro dos últimos anos os modos de presença de produções que se ocupam da trivialidade cotidiana e tratam de universos atinentes ao que se entende como o homem sem qualidades. ${ }^{2}$

O trabalho Pai e filha, Não por acaso: cotidiano, lugar e deslugar consiste em um fragmento dos diversos estudos nos quais tenho buscado aproximar e, em certa extensão, comparar o cinema do cotidiano e da banalidade realizado pelo cineasta japonês Yasujiro Ozu do cinema de alguns dos diretores brasileiros contemporâneos que também focam suas lentes na miudeza rotineira de cada dia; a despeito da diversidade das especificidades contextuais de ordem cultural e cronotópica, tal tentativa de análise comparativa justifica-se, entendo, tanto no sentido de orientar a definição de percursos investigativos, quanto no intuito de definir categorias iniciais que viabilizem e facilitem a detecção e a identificação dos traços estéticos e temáticos que caracterizam, em termos fílmicos e cinematográficos, a emergência desse discurso do cotidiano e da intimidade e o entendimento a respeito de suas articulações com a dita realidade social.

O objeto cotidiano, no âmbito das pesquisas que venho desenvolvendo, está entendido e tomado enquanto o espaço em que privilegiadamente se manifesta o banal, o trivial, o repetitivo - ou aquilo 
que aparentemente se apresenta como banal, trivial e repetitivo. Dentro desse universo, busco detectar e destacar, nas obras fílmicas selecionadas, também as camadas do despercebido, do invisível, do estranho - à procura daquilo que, por entre silêncios e lacunas, resta inédito e germina como invenção nas imagens do dia a dia. Trato, predominantemente, de filmes que, tais como Pai e filha3 (1949, Yasujiro Ozu), e Não por acaso (2007, Philippe Barcinski), abordados no presente estudo, são ambientados em cenários urbanos e ocupam-se da rotina de personagens inseridas no contexto daquilo que, contemporaneamente, ainda permanece da família nuclear freudiana e que se situam, em termos socioeconômicos, nas gradações do que se entende hoje pela classe média (distribuída em faixas que vão da média baixa à média alta).

$\mathrm{Na}$ esteira da questão cinema e cotidiano, trato neste texto de uma dimensão das imagens do dia a dia que muito me interessa e tem afetado de modo cada vez mais decisivo o percurso das investigações que venho desenvolvendo, uma dimensão que me parece ter estreita relação com a contemporaneidade: a noção de deslugar - ou, melhor, daquilo que estou chamando deslugar -, e que diz respeito à significativa condição de personagens que se encontram e se movimentam em deslugar, colocadas em situação de deslugar. A partir daí, penso, começa a se configurar e a se estabelecer, em certa extensão, uma poética, uma estética do deslugar no cinema do cotidiano.

As tentativas de apreensão, circunscrição e descrição daquilo que entendo como deslugar, com vistas a um primeiro esboço de conceituação, têm sido paulatinamente alargadas e intensificadas no decorrer de minhas pesquisas. A temática será abordada, aqui, a título de experimento e especulação, com o objetivo de introduzir e colocar em discussão aspectos de uma proposição que ainda está engatinhando, buscando apoio para se colocar de pé - longe ainda, portanto, de se encontrar no ponto de se colocar plenamente a caminho e bem distante das vias de elaboração que almeja alcançar. Aprofundamentos, espero, serão apresentados em textos futuros.

Ainda que me tenha sido relativamente fácil divisar no âmbito dos filmes que venho estudando as manifestações da situação de deslugar, parece-me particularmente difícil precisar as condições de emergência desse fenômeno e a dimensão específica de sua caracterização na perspectiva dos conceitos de não lugar e entre-lugar.
3. O título original - Banshun traduz-se literalmente por Primavera tardia; filme baseado na novela Chichi to musume (Pai e filha), de Kazuo Hirotsu. 
Assim, ainda que não caiba neste artigo apresentar uma reflexão linear e totalizadora a respeito desses dois termos, tampouco traçar e demonstrar seus percursos evolutivos, perseguindo e indicando pontos em que se tangenciam ou se afastam, remeto ligeira e resumidamente às características básicas de cada um deles e a alguns de seus desdobramentos principais - para tentar, pela diferença, clarear o que estou tentando dizer sobre deslugar e para situar, ainda que precariamente, de onde estou falando. Avisada, naturalmente, da possibilidade de talvez estar mesmo, em última análise, já falando a partir de um deslugar, de uma posição de instabilidade.

Quando o antropólogo Marc Augé discute a noção de lugar, o faz a partir da noção de "lugar antropológico":

Reservamos o termo "lugar antropológico" àquela construção concreta e simbólica do espaço que não poderia dar conta, somente por ela, das vicissitudes e contradições da vida social, mas à qual se referem todos aqueles a quem ela designa um lugar, por mais humilde e modesto que seja. É porque toda antropologia é antropologia da antropologia dos outros, além disso, que o lugar, o lugar antropológico, é simultaneamente princípio de sentido para aqueles que o habitam e princípio de inteligibilidade para quem o observa.

(...) Esses lugares têm pelo menos três características comuns. Eles se pretendem (pretendem-nos) identitários, relacionais e históricos. (AUGÉ, 2010, P.51-2)

Denomina-se lugar antropológico ao espaço 1) identitário "nascer é nascer num lugar, ser designado à residência. Nesse sentido, o lugar de nascimento é constitutivo da identidade individual" (AUGÉ, p.52); 2) relacional, articulado em uma teia de relações e configurado em acordo com determinada identidade - definida pelos acontecimentos de seu passado e de seu momento presente e, em certa extensão, parece-me, também por suas perspectivas de futuro "num mesmo lugar podem coexistir elementos distintos e singulares, sem dúvida, mas sobre os quais não se proíbe pensar nem as relações nem a identidade partilhada que lhes confere a ocupação do lugar comum" (p.53); e 3) histórico, detentor de uma história "o lugar é necessariamente histórico a partir do momento em que, conjugando identidade e relação, ele se define por uma estabilidade mínima (...)é histórico na exata proporção em que escapa à história como ciência. 
(...) O habitante do lugar antropológico não faz história, ele vive na história" (p.53).

Origina-se desses pressupostos o conceito de não lugar - desenvolvido por Augé e empregado como forma de identificar lugares que não permitem criar identidade, que se constituem como espaços de anonimato no cotidiano. Não lugares são espaços que não detêm história; não articulam teias de relações; e não desenvolvem processos identitários próprios. ${ }^{4}$ Espaços de trânsito, de nomadismo. Lugares não-fechados, não-imanentes, não-hierarquizados, sem princípios fixos, ao contrário: campos abertos a movimentações de preenchimentos/esvaziamentos, concentrações/dispersões, continuidades/descontinuidades.

Já a discussão a respeito daquilo que se pode definir como entre-lugar vincula-se a sistemas de dispersão, à articulação de teias de relações esgotáveis e perecíveis, estabelecidas a partir de agenciamentos, à noção de espaços estriados e espaços lisos, a intersecções e avizinhamentos e contempla o entre-lugar como não fixidez, como possibilidade estratégica que permite a ativação de temas incompatíveis, a introdução de um mesmo tema em conjuntos e situações diferentes. ${ }^{5}$

Entre-lugares configuram-se como espaços de negociação e afirmam-se como movimento e enquanto produtores de figuras complexas, ambíguas e multifacetadas de diferença e de identidade; são sítios onde se articulam elementos do passado e do presente, do interior e do exterior, da inclusão e da exclusão: caracterizam-se pelo interstício, pela fenda, pela brecha.

Na contemporaneidade os lugares, entre-lugares e não lugares se estabelecem tanto física quanto virtualmente. A conectividade e os efeitos de globalização - virtuais ou não - propiciados pelas tecnologias, digamos, tradicionais (rádio, televisão, telefone fixo), e principalmente pelas consideradas como novas ou relativamente recentes (telefonia móvel, internet, cinema IMAX, etc.) estabelecem múltiplas e inusitadas redes de lugares - de forma que é também possível que a movimentação resultante, em alguns casos, crie e estabeleça (provisoriamente ou não) espaços que são não lugares a partir dos quais se originam nós ou feixes de nós; em virtude das topologias de compartilhamentos e vizinhanças instauradas por essas redes, os espaços intrincados desses nós constituem-se em entre-lugares. Eventualmente, esses tais entre-lugares se transmudam em
4. "Se um lugar pode se definir como identitário, relacional e histórico, um espaço que não pode se definir nem como identitário, nem como relacional, nem como histórico definirá um não lugar. A hipótese aqui defendida é a de que a supermodernidade é produtora de não lugares, isto é, de espaços que não são em si lugares antropológicos e que, contrariamente à modernidade baudelairiana, não integram os lugares antigos: estes, repertoriados, classificados e promovidos a 'lugares de memória', ocupam aí um lugar circunscrito e específico. Um mundo onde se nasce numa clínica e se morre num hospital, onde se multiplicam, em modalidades luxuosas ou desumanas, os pontos de trânsito e as ocupações provisórias (as cadeias de hotéis e os terrenos invadidos, os clubes de férias, os acampamentos de refugiados, as favelas destinadas aos desempregados ou à perenidade que apodrece), onde se desenvolve uma rede cerrada de meios de transporte que são também espaços habitados (...)." (AUGÉ, 2010, p. 73-4)

5. A ideia de entre-lugar, presente na obra de diversos pesquisadores, nos termos aqui colocados vincula-se a Michel Foucault e a Deleuze e Guattari. Já o entre-lugar na cultura é longamente discutido por Homi Bhabha; no âmbito da imagem cinematográfica, a noção do entre-lugar a dimensão atinente ao entre-imagens - é abordada por Raymond Bellour. 
lugares e não lugares que vão, por seu turno, originar nova gama de nós - e assim sucessivamente.

Bem diversa das noções topológicas de entrelugar e não lugar é, parece-me, a tipologia, a estruturação e a configuração da noção de deslugar no cotidiano dos tempos que correm. Características da contemporaneidade e de natureza física ou virtual, as duas primeiras podem, penso, ser transportadas para o âmbito psíquico-intelecto-emocional das relações humanas em seus desdobramentos sócio-afetivo-amorosos e examinadas a partir dessa perspectiva. Já o deslugar, objeto de interesse desse artigo, seria de natureza exclusivamente psíquico-intelecto-emocional; e, não obstante me pareça um fenômeno preponderantemente característico da contemporaneidade, seria atemporal.

O estar em deslugar define-se, basicamente, pelo nem/nem. Trata-se de uma situação, de uma posição psíquica e emocional definida pelo não estar dentro e o não estar fora, simultaneamente. Enquanto a noção de não lugar relaciona-se ao estar de passagem, ao não pertencer e a de entre-lugar contempla o pertencer a dois ou mais lugares, o estar posicionado entre duas ou mais situações, a ideia de des-lugar implica um estar des-acertado, des-encaixado: um alojamento parcial, um descompasso entre um espaço situacional e seu ocupante.

O estar em deslugar é da ordem do desconforto, do estranho. Do indizível, do inominável. É a indeterminação perturbadora, desestabilizadora: não é estar dentro, não é estar fora, não é estar entre dentro e fora. É o é mas não é, é o ser sem ser. Achar-se em deslugar é estar colocado em determinada condição - e marcadamente bem colocado, diga-se - sem estar adequadamente nela situado: tipo não pertencer pertencendo e pertencer sem pertencer.

Encontrar-se em deslugar, em situação de deslugar seria estar simultaneamente ocupando de direito e de fato algum lugar/posição e não estar pertencendo a esse lugar: ocupando-o sem preenchê-lo, talvez, não à vontade ali, não efetivamente acolhido ou acomodado nesse tal espaço. $\mathrm{O}$ sujeito pode, preenche todas as condições que lhe facultam ocupar determinada posição, mas a ela não se integra: à moda de um desejo que tem existência, mas, cuja movimentação em termos de deslizamentos e deslocamentos não flui ou, ao menos, quando acontece essa movimentação ela não se dá de maneira fluída.

Talvez seja a não-pertença na pertença, o não pertencimento no 
pertencimento. É daí que vem o desconforto, a presença de ambigüidades desconcertantes e desestabilizadoras e a confusão de fluxos no deslugar - além da permanente tensão resultante do atrito entre linhas de força que se alternam em correntes de impossibilidade/possibilidade/despossibilidade.

$\mathrm{Na}$ esteira das relações familiares, particularmente, nos tempos em que vivemos o advento do deslugar é, senão predominante, ao menos bastante comum e de fácil detecção. Vejamos então, na sequência, os lugares do cotidiano e do deslugar nos filmes em tela.

\section{Pai e filha não por acaso?}

Pai e filha (Japão, 1949, Yasujiro Ozu), cidade de Kamakura nos idos do pós-guerra: imagens do cotidiano de pai e filha desconcertados ante a probabilidade da separação anunciada, ponto que interrompe fluxos de convivência e rotina em curso desde sempre: o pai quer que a filha deixe a casa paterna para se casar e a filha reluta. Não por acaso (Brasil, 2007, Philippe Barcinski), cidade de São Paulo na contemporaneidade: imagens do cotidiano de pai e filha unidos - e reunidos - pelo acaso e desorientados pelo advento do encontro inesperado, ponto de convergência que deflagra fluxos de convivência e rotina que nunca antes aconteceram: a filha quer se estabelecer na casa paterna e o pai reluta.

Distintos e distantes geográfica e cronologicamente, dois diretores focando as lentes na rotina das relações familiares, na casa, no homem comum. Banalidade, repetição, topicalizações: dois pais, duas filhas, dois lugares. Dúvidas, hesitações, perplexidades, lugares em trânsito. Sutil tensão, leve desconforto - camuflados, que seja, em algum estágio entre o volátil e o palpável, mas sensíveis e permanentemente atualizados.

$\mathrm{Na}$ tela de cada um destes dois filmes as configurações imagéticas delineiam, poeticamente, o lugar do deslugar no cotidiano - ou, como já frisei, daquilo que estou, provisoriamente e na falta de um significante mais apropriado, denominando deslugar. É da estrutura do deslugar a dificuldade - senão a impossibilidade, mesmo - do nomear, a ausência de significante, o estado de quase-evanescência. Trata-se, aqui, do deslugar como sintoma e do sintoma como deslugar - na medida em que o sintoma, emergência do real, sinaliza 


\footnotetext{
6. Esquizofrenias não no sentido restritivo do termo, que tende a privilegiar a ideia de patologia, mas no sentido amplo, que entende a ideia de esquize como o desvio do olhar. O temo esquizofrenia, aqui, está sendo tomado enquanto processo de descodificação e desterritorialização, que favorece/impulsiona a atividade revolucionária - no sentido em que o empregam Deleuze e Guattari (DELEUZE, 2000, p.35-6).
}

que há algo, digamos, "fora de lugar", fora do campo simbólico. Deslugar entendido em uma acepção diversa da mencionada noção do não-lugar, que designa espaços de passagens, lugares de idas e vindas incapazes de dar forma a qualquer tipo de identidade e que pressupõem o transeunte, o viajante; próximo, mas também distinto, da idéia de entre-lugar, que designa, por sua vez, espaços intermediários entre dois ou mais lugares, estados ou situações e que pressupõe certo ajustamento, uma forma de acolhida na intermitência, o alojar-se no entremeio da justaposição. Deslugar que pressupõe não-acolhimentos, desalojamentos, desajustamentos - e uma espécie de permanente inadequação, de não-descanso: um desapaziguamento latente ou manifesto - desdramatizado, plácido até, por vezes, mas sempre presente.

Atravessado pelo desconforto, pela constante sensação de estranhamento, inadequação e impertinência (ou ex-pertinência), o indivíduo em estado de deslugar movimenta-se pouco à vontade no cotidiano, por entre "trancos e barrancos". Um cotidiano que se lhe apresenta embaçado, em fluxos sempre embaraçados e congestionados por hesitações e dúvidas, por deslocamentos superpostos e condensações empedradas. Deslugar cujo rosto distópico e desterritorializado surge no "real" de esquizofrenias ${ }^{6}$ de toda sorte: anorexias e bulimias tardias, infâncias abreviadas e adolescências eternizadas, corpos martirizados; mas também no devir e no gozo inesperado da invenção e da criação, do percurso por caminhos que desvelam paisagens outras.

Metaforicamente, a partir dos lugares que se estabelecem, vertical e horizontalmente, no bojo dos nós que regulam as teias dos relacionamentos sociais que se estendem no dia a dia dos universos fílmicos de Pai e filha e de Não por acaso, nas brechas que perfazem estas mesmas teias instalam-se, transversalmente, os deslugares a que me refiro. Deslugares que se manifestam e se apresentam formalmente, nos dois filmes em questão, de diversas maneiras - mas particular e especialmente por meio de lacunas e descontinuidades, da visibilidade conferida ao silêncio, ao átimo, às inversões. Deslugares que acabam por se definir tanto como espaços de desconforto e estranhamento, instabilidade e provisoriedade em oposição ao conforto e familiaridade, estabilidade e permanência dos lugares pré-dimensionados, quanto como possibilidades efetivas de movimento e abertura em contraposição à estagnação e à clausura 
- e, talvez, como possibilidades de articulações de um discurso que não seja semblante.

Acontecimentos típicos do desenrolar corriqueiro da vida (encontros e desencontros, casamentos e descasamentos, interrupções, retomadas, encerramento e início de relacionamentos familiares ou amorosos, mortes, mudanças domiciliares, etc.) modificam, por entre deslocamentos e condensações, o curso e o escoamento de uma diversidade de fluxos cotidianos que se entrecruzam e se interpenetram na narrativa fílmica de Pai e filha e na de Não por acaso. As coisas saem do lugar habitual, promovendo e desencadeando alterações significativas na rotina, no dia a dia de determinadas personagens - alterações que contaminam e causam desacerto e desconforto na vida não apenas das personagens diretamente afetadas e envolvidas, mas também na de toda uma série de personagens outras. Relações afetivo-familiares e domésticas, entrelaçadas ao mundo do trabalho, são enfocadas em primeiro plano, intensificando o jogo interiores/exteriores ao ponto de as figuras da casa e da rua serem alçadas quase à condição de personagens.

No caso de Pai e filha, imagens em claro/escuro desvelam interiores domésticos alternando-se com espaços de céu riscados por fios de luz, estações ferroviárias, trens em movimento, interiores de vagões repletos de pessoas penduradas em argolas a balançar-se na cadência do movimento ritmado do comboio. No universo de Não por acaso, as ruas da cidade de São Paulo invadem as telas de computadores espalhadas e amplificadas por toda a tela do filme, alternando-se com imagens de locais de trabalho que se misturam a imagens de interiores domésticos em processo de transição e mudança: residências sendo desocupadas ou prestes a serem re-ocupadas, casas e apartamentos vazios ou desordenados, bagunçados por objetos e pertences fora de lugar, peças de mobília abandonadas e armários deixados para trás, janelas envidraçadas descortinando espaços de céu azul.

O sintomático, aqui, consiste não apenas nos deslugares que se delineiam na tela dos dois filmes, mas também na inversão de ritmo e direção que se instala poeticamente nas e por entre as imagens de ambos: enquanto no "ontem” do cotidiano do Japão do pós-guerra tematizado e figurativizado por Ozu em Pai e filha o "estranho" (o inusitado, o diferente) consiste na velocidade assolando o espaço da contemplação, no "hoje" (no "agora") do cotidiano do Brasil con- 
temporâneo tematizado e figurativizado por Barcinski em Não por acaso o "estranho" (o inusitado, o diferente, a mudança) consiste, por seu turno, na emergência do intervalo, da lacuna - da lentidão - assolando o espaço da velocidade. Neste último caso, a premência da brecha que faz furo na tubulação comprimida e saturada dos fluxos que se articulam em redes interrompe o curso frenético da velocidade cotidiana - congestionando e instalando o caos, mas também promovendo afrouxamentos e lacunas que ao mesmo tempo e na medida em que desaceleram o ritmo acabam justamente por criar espaços de reconfigurações que permitem o descongestionamento, a retomada da fluidez, o escoamento dos fluídos.

Ao final do filme de Ozu, pai e filha restam apartados, prestes a iniciar cada qual uma nova viagem; a última sequência do filme de Barcinski encontra filha e pai pedalando lado a lado, cada qual montado em sua bicicleta. O lugar da mãe, em ambos os filmes, é vago, rarefeito; também nos dois universos fílmicos a casa, o espaço doméstico se transmuda e reconfigura - enquanto a rua, o local de trabalho, o espaço público, enfim, renegociado, ganha feições e prioridades inusitadas. Um ar de nomadismo impregna, fortemente, as cenas derradeiras. Não por acaso, parece-me.

Já o deslugar, prenúncio e potência, lá segue com eles e cá segue conosco. Desterritorializado, devir, cotidiano. Sintoma da contemporaneidade, talvez. 


\section{Bibliografia}

AUGÉ, M. Não-lugares: introdução a uma antropologia da sobremodernidade. Campinas: Papirus, 2010.

BHABHA, H. K. O local da cultura. Belo Horizonte: Editora da UFMG, 2001.

BACHELARD, G. A poética do espaço. São Paulo: M. Fontes, 2000.

BALLÓ, J. Imágenes del silencio: los motivos visuales en el cine. Barcelona: Anagrama, 2000.

BARTHES, R. Como viver junto: simulações romanescas de alguns espaços cotidianos. São Paulo: Martins Fontes, 2003.

BAUMANN, Z. Vida líquida. Rio de Janeiro: Zahar, 2007.

BELLOUR, R. Entre-imagens: foto, cinema, vídeo.

Campinas: Papirus, 1997.

BLANCHOT, M. "A fala cotidiana”. (In: A conversa infinita 2. A experiência limite.) São Paulo: Escuta, 2007.

CERTEAU, M. A invenção do cotidiano: artes de fazer.

Petrópolis: Vozes, 2008.

DELEUZE, G. Conversações. Rio de Janeiro: Ed. 34, 2000.

DELEUZE, G.; GUATTARI, F. Mil platôs - capitalismo e esquizofrenia. Rio de Janeiro: Ed. 34, 1995.

FISCHER, S. “Azuis de Ozu e de Aïnouz.” (In: MOURÃO, D. et all. (Orgs) X Estudos de cinema Socine). São Paulo: Socine, 2010.

FLOCH, J. M. “Alguns conceitos fundamentais em semiótica geral". (In: Documentos de estudo do Centro de Pesquisas Sociossemióticas, 1) São Paulo: Martins Fontes, 2001.

FLOCH, J. M. Identités visuelles. Paris: P.U.F, 2001, 1995.

FRANÇA, V.; GUIMARÃES, C. (Orgs) Na mídia, na rua: narrativas do cotidiano. Belo Horizonte: Autêntica, 2006.

FREUD, S. “O estranho” (In: Obras psicológicas completas de Sigmund Freud). Rio de Janeiro: Imago, 1996.

LACAN, J. “As formações do inconsciente” (In: O Seminário, Livro 5). Rio de Janeiro: Jorge Zahar, 1996.

LACAN, J. Os complexos familiares. Rio de Janeiro: Jorge Zahar, 1987

LACAN, J. Escritos. São Paulo: Perspectiva, 1978.

LANDOWSKI, E. Presenças do outro. São Paulo: Perspectiva, 2002. 
LOPES, D. "Nem favela, nem sertão ou por um cinema do cotidiano”. (In: CATANI, A. et al. [Orgs] Estudos Socine de cinema, VI). São Paulo: Nojosa Edições, 2005.

MAFFESOLI, M. O tempo das tribos - o declínio do individualismo nas sociedades de massa.

Rio de Janeiro: Forense Universitária, 2006.

NAGIB, L. e PARENTE, A. (Orgs) Ozu, o extraordinário cineasta do cotidiano. São Paulo: Marco Zero/Cinemateca Brasileira/Aliança Cultural Brasil-Japão, 1990.

ROUDINESCO, E. A família em desordem. Rio de Janeiro: Jorge Zahar, 2003.

SANTOS, A. Yasujiro Ozu: elogio del silencio. Madrid: Cátedra, 2005.

XAVIER, I. O discurso cinematográfico: a opacidade e a transparência. São Paulo: Paz e Terra, 2005.

XAVIER, I. (Org.) O cinema brasileiro moderno.

Rio de Janeiro: Graal, 2001.

YOSHIDA, K. O anticinema de Yasujiro Ozu. São Paulo: Cosac \& Naify, 2003. 